\title{
Endophytic Fungi from Sorghum bicolor (L.) Moench: Influence of Genotypes and Crop Systems and Evaluation of Antimicrobial Activity
}

Ruth Terezinha Rodrigues, Márcia Marília de Souza Silva, Douglas Moreira de Oliveira, Josimar Bento Simplício, Cynthia Maria Carneiro Costa and Virginia Medeiros de Siqueira

Federal Rural University of Pernambuco, Academic Unit of Serra Talhada, 56909-535, Serra Talhada, Pernambuco, Brazil

\begin{abstract}
Endophytic fungi (EF) colonize plant tissues without causing damage; this relationship brings benefits to both, including a greater resistance to environmental stresses, but the influence of genotypes and culture system in endophytic community is still unraveled. Thus, this work aimed to study EF from Sorghum bicolor and correlate to its genotypes submitted to different culture systems; their potential to produce antimicrobial compounds was also evaluated. To optimize the production of metabolites, four isolates were submitted to liquid medium and the crude extracts of different culture times were analyzed. EF of leaves of Qualimax and SF15 genotypes were isolated after superficial disinfection. Fungal identification was made using classical taxonomy. As results, the traditional system presented the lowest number EF isolates, while the minimum system showed the highest. The genera Aspergillus, Fusarium, Penicillium, Cladosporium, Curvularia and Syncephalastrum were found; Aspergillus spp. was pointed out as a predominant endophyte of genotype Qualimax. Among the 25 endophytes submitted antimicrobial activity assay in solid medium, 21 presented antibacterial activity against at least one bacterium with the highest inhibition zone of $29.3 \mathrm{~mm}$ of diameter against Staphylococcus aureus. All EF submitted to liquid medium kept the capacity to produce antibacterial metabolites. In conclusion, regardless of genotype and culture system, sorghum is colonized by different EF, mainly Aspergillus spp. EF from leaves of $S$. bicolor produce antibacterial compounds and their biotechnological applications can be explored in future.
\end{abstract}

Key words: Plant microbiome, genotypes, sorghum, semi-arid, antimicrobial compounds.

\section{Introduction}

Sorghum bicolor (L.) Moench (Family Poaceae) is popularly known in Brazil as "sorgo" or "milho-zaburro" and represents one of the most important fodder supports for livestock in the Brazilian semi-arid region, once it is a crop of high potential for production of green mass in this climatic condition. Additionally, S. bicolor is a xerophytic plant with low requirements in soil fertility and high tolerance to drought and saline stresses [1].

Due to the advantages in its use for forage, different genotypes of sorghum has been introduced in the market, but information about these genotypes and

Corresponding author: Virginia Medeiros de Siqueira, professor, research fields: environmental microbiology, endophytic fungi, bioprospection and bioactive compounds. their interactions with microorganisms, such as endophytic fungi (EF), have been poorly reported [2]. Diverse researches about fungi associated with well-characterized and economically important plants often reveal new taxa and new distributions of the known species. These studies contribute to the knowledge of interactions between different plants and microorganisms, contribute to the study of biodiversity, and reveal possible microorganisms that can be biotechnologically exploited [3, 4]. In addition, researches in this area can also provide a better understanding of the different types of genotypes submitted to different crop systems and their influence in the plant endophytic microbiota.

In recent years, several studies have been carried out to explore the diversity of EF of crop plants, as well as the application of these microorganisms in the 
improvement of banana, passion fruit, citrus, sugar cane, for example [5-7]. Zida et al. (2014) [8] recently published interesting results about $\mathrm{EF}$ of $S$. bicolor in Burkina Faso in Africa, but researches about EF of $S$. bicolor are still rare in Brazil, thus arising the need for studies in this area.

The present work aimed to study EF associated with two genotypes of forage S. bicolor submitted to three different crop systems in the Brazilian northeastern semi-arid region, in the municipality of Serra Talhada, state of Pernambuco. In addition, the potential production of antimicrobial compounds by the EF was also evaluated.

\section{Materials and Methods}

\subsection{Cropping Systems, Genotypes and Sample Collection}

Two sorghum genotypes (Qualimax and SF-15) submitted to three different crop systems (conventional, minimum cultivation and no-tillage) composed the experimental treatments.

The collection of plant material was carried out at the Experimental Station of the Institute of Farming Research of Pernambuco (IPA), Serra Talhada, state of Pernambuco, Brazil. Leaves of five healthy adult plants from each genotype submitted to a different crop system were randomly collected, labeled and placed into plastic bags previously autoclaved. From each sorghum plant, three leaves were randomly selected, from which five fragments were removed, thus totaling 15 leaf fragments of each individual plant, and 75 leaf fragments of each genotype. Two genotypes submitted to three cropping system were analyzed, totaling 450 fragments of sorghum leaves.

The samples were sent under refrigeration to the Laboratory of Microbiology of the Federal Rural University of Pernambuco, Academic Unit of Serra Talhada, Brazil, for further analyses.

\subsection{Isolation, Quantification and Identification of EF}

Endophytic fungal isolation was performed according to Araújo et al. (2002) [9]. For elimination of epiphytic microorganisms, the plant material was submitted to the surface sterilization process in which sorghum leaves were washed in running water, followed by immersion in $70 \%$ ethanol for $1 \mathrm{~min}$, in sodium hypochlorite (2\%-2.5\% active chlorine) for 4 min, in $70 \%$ ethanol for $30 \mathrm{~s}$ and washed three distilled and sterilized water.

After superficial sterilization, the samples were cut into $0.5 \mathrm{~cm}^{2}$ fragments and aseptically transferred to Petri dishes containing Sabouraud Dextrose Agar (SDA) culture medium (peptone 10 $\mathrm{g} / \mathrm{L}$, dextrose $40 \mathrm{~g} / \mathrm{L}$, agar $15 \mathrm{~g} / \mathrm{L}, \mathrm{pH}$ 5.6), supplemented with chloramphenicol $(100 \mu \mathrm{g} / \mathrm{mL})$ to suppress bacterial growth. Petri dishes were incubated at $28{ }^{\circ} \mathrm{C}$ up to $30 \mathrm{~d}$, checked daily and any fungal colony present was isolated, purified and preserved for further identification. Percentage colonization was defined as the total number of fragments colonized by fungi in relation to the total number of fragments $\times 100$ [10]. The control of surface sterilization efficiency was confirmed by the inoculation of the last wash water in Petri dishes with the Agar Nurtrient (AN) culture medium (peptone $5 \mathrm{~g} / \mathrm{L}$, yeast extract $3 \mathrm{~g} / \mathrm{L}$, sodium chloride $5 \mathrm{~g} / \mathrm{L}$, agar $15 \mathrm{~g} / \mathrm{L}, \mathrm{pH} 6.8$ ).

The identification of EF was done using macroscopic characteristics of the colonies (color, aspect, consistency and presence of pigmentation) and microscopic characteristics (morphology of vegetative and reproductive structures). The following literature was used for identification [11-15]. Potato Dextrose Agar (PDA) (potato infusion $200 \mathrm{~g} / \mathrm{L}$, dextrose $20 \mathrm{~g} / \mathrm{L}$, agar $15 \mathrm{~g} / \mathrm{L}, \mathrm{pH}$ 5.6), SDA and Water Agar were utilized and incubation was at $28 \pm 2{ }^{\circ} \mathrm{C}$ during up to $30 \mathrm{~d}$.

\subsection{Screening and Agar Plug Assay}

Twenty five purified EF were selected and submitted to agar plug assay [16] which is a technique that permits a rapid and qualitative selection of the 
fungi capable to inhibit other microorganisms.

The fungi were grown on SDA at $28^{\circ} \mathrm{C}$ during $7 \mathrm{~d}$ and, after this period, discs (6 $\mathrm{mm}$ diameter) of mycelium agar were cut and transferred onto the culture media Müeller-Hinton Agar (peptone $3.0 \mathrm{~g} / \mathrm{L}$, peptone of casein $17.5 \mathrm{~g} / \mathrm{L}$, agar $15 \mathrm{~g} / \mathrm{L}, \mathrm{Ca}^{2+} 20-25$ $\left.\mathrm{g} / \mathrm{L}, \mathrm{Mg}^{2+} 10-12.5 \mathrm{~g} / \mathrm{L}, \mathrm{pH} 7.4\right)$ previously spread with microorganisms test: Staphylococcus aureus (ATCC-6538), Bacillus subtilis (UFPEDA-16), Escherichia coli (ATCC-25922) and Klebsiella pneumoniae (ATCC-29665). Petri dishes were incubated at $37{ }^{\circ} \mathrm{C}$ for $24 \mathrm{~h}$ and the antimicrobial activity was confirmed by the visualization and measurement of inhibition zones.

The tests were performed in triplicate and the measurements of the inhibition zones were expressed in millimeters by means of triplicates.

\subsection{Fermentation and Disk Diffusion Assay}

The EF that showed the best activity in the agar plug assay were evaluated in liquid culture medium at different time of cultivation. This provides a way to confirm if the fungi are still able to produce the bioactive compound in liquid culture medium and select the best time for the production of the bioactive metabolites. For this, five plugs $(6 \mathrm{~mm}$ in diameter) of fungal growing culture were inoculated into $500 \mathrm{~mL}$ Erlenmeyer flasks containing $250 \mathrm{~mL}$ of Broth Sabouraud. The cultures were submitted to a rotary shaker at $180 \mathrm{rpm}$ at room temperature $(28 \pm$ $2{ }^{\circ} \mathrm{C}$ ) during $120 \mathrm{~h}$. After 72,96 and $120 \mathrm{~h}$ of cultivation, an aliquot of $10 \mathrm{~mL}$ were transferred into plastic tubes and centrifuged at $225 \mathrm{~g}$ for $15 \mathrm{~min}$ to separate fungal biomass. After this, $20 \mu \mathrm{L}$ of the supernatant was used for the antimicrobial activity test using the disk diffusion method [17]. The tests were performed in triplicate and the measurements of the inhibition zones were expressed in millimeters by means of triplicates.

\section{Results and Discussion}

\subsection{Quantification and Diversity of EF}

As all living organisms, plants are colonized by a wide variety of microorganisms that constitute their microbiome. The sum of the plant plus its microbiome composes the holobiont, which present interdependent and complex dynamics such as the ecological systems of higher organisms [18]. The holobiont of a vegetable is a good example of how the interaction between the plant and its microbiome brings advantages to its constituents. In the case of plants, the microbiome is composed of the rhizosphere, phylosphere and endosphere [19]; endophytic microorganisms compose the endosphere.

From 450 fragments of leaves of S. bicolor, 107 fragments of genotype Qualimax and 81 fragments of genotype SF-15 were colonized by EF, representing a colonization rate of $47.5 \%$ and $36 \%$, respectively. The SF-15 genotype presented the higher number of EF (38) when submitted to conventional planting, followed by Qualimax that presented $37 \mathrm{EF}$ when submitted to both conventional and minimum cultivation systems. It was registered the lowest colonization rate (17.3\%) in SF-15/no-tillage sorghum (Table 1).

Table 1 Quantification* of endophytic fungi (EF) from leaves of two genotypes of Sorghum bicolor submitted to different crop systems.

\begin{tabular}{lllll}
\hline Crop system & Qualimax & Colonization rate (\%) & SF-15 & Colonization rate (\%) \\
\hline No-tillage & 33 & 44.0 & 13 & 17.3 \\
Minimum cultivation & 37 & 49.3 & 30 & 40.0 \\
Conventional & 37 & 49.3 & 38 & 50.6 \\
Total & 107 & 47.5 & 81 & 36 \\
\hline
\end{tabular}

*Number of fungal colonies. 

and Crop Systems and Evaluation of Antimicrobial Activity

Based on their macromorphological characteristics, 61 fungal isolates were selected and purified, from which 31 were taxonomically identified. The genera Aspergillus, Fusarium, Penicillium, Cladosporium, Curvularia and Syncephalastrum were found as endophytic of leaves of sorghum (Tables 2 and 3). Thirty isolates were classified as "filamentous fungi" or "yeast" because they did not develop reproductive structures.

Among the identified fungal isolates, Aspergillus was the genera presented in all analyzed conditions (except for genotype SF-15/minimum cultivation) with 14 occurrences, 11 from genotype Qualimax and three from genotype SF-15; A. niger was the most presented species. Zida et al. (2014) [8] found different results in a study about EF from leaves, roots and stem of sorghum that showed Fusarium, Curvularia and Penicillium as the most represented genera, but not Aspergillus. These same authors also pointed out Leptosphaeria sacchari, Gloeocercospora sorghi, Acremonium and Bipolaris as endophytic fungal commonly isolated from sorghum leaves, and Penicillium, Curvularia and Fusarium as not specific to a given host tissue. In a study about EF from roots

Table 2 EF isolated from leaves of S. bicolor-genotype Qualimax.

\begin{tabular}{|c|c|c|}
\hline Isolate number & Crop system & Identification \\
\hline 1 & \multirow{11}{*}{ No-tillage } & A. niger \\
\hline 2 & & A. flavus \\
\hline 3 & & Curvularia sp. \\
\hline 4 & & A. niger \\
\hline 5 & & Fusarium sp. \\
\hline 6 & & A. flavus \\
\hline 7 & & A. niger \\
\hline 8 & & A. niger \\
\hline 9 & & Zygomycota \\
\hline 10 & & Filamentous fungi \\
\hline 11 & & Filamentous fungi \\
\hline 12 & \multirow{12}{*}{ Minimum cultivation } & Filamentous fungi \\
\hline 13 & & Filamentous fungi \\
\hline 14 & & Filamentous fungi \\
\hline 15 & & Fusarium sp. \\
\hline 16 & & Fusarium sp. \\
\hline 17 & & Filamentous fungi \\
\hline 18 & & Filamentous fungi \\
\hline 19 & & A. niger \\
\hline 20 & & Filamentous fungi \\
\hline 21 & & Cladosporium sp. \\
\hline 22 & & Cladosporium sp. \\
\hline 23 & & Zygomycota \\
\hline 24 & \multirow{9}{*}{ Conventional system } & A. costaricaensis \\
\hline 54 & & Filamentous fungi \\
\hline 55 & & Filamentous fungi \\
\hline 56 & & A. niger \\
\hline 57 & & Filamentous fungi \\
\hline 58 & & A. niger \\
\hline 59 & & Aspergillus sp. \\
\hline 60 & & Filamentous fungi \\
\hline 61 & & Penicillium sp. \\
\hline
\end{tabular}


Table 3 EF isolated from leaves of $S$. bicolor-genotype $S F-15$.

\begin{tabular}{|c|c|c|}
\hline Isolate number & Crop system & Identification \\
\hline 24 & \multirow{7}{*}{ No-tillage } & Filamentous fungi \\
\hline 25 & & Filamentous fungi \\
\hline 26 & & Cladosporium sp. \\
\hline 27 & & Filamentous fungi \\
\hline 28 & & A. niger \\
\hline 29 & & Filamentous fungi \\
\hline 30 & & Filamentous fungi \\
\hline 40 & \multirow{13}{*}{ Minimum cultivation } & Cladosporium sp. \\
\hline 41 & & Filamentous fungi \\
\hline 42 & & Fusarium sp. \\
\hline 43 & & Filamentous fungi \\
\hline 44 & & Filamentous fungi \\
\hline 45 & & Filamentous fungi \\
\hline 46 & & Penicillium sp. \\
\hline 47 & & Filamentous fungi \\
\hline 48 & & Filamentous fungi \\
\hline 49 & & Filamentous fungi \\
\hline 50 & & Syncephalastrum sp. \\
\hline 51 & & Zygomycota \\
\hline 52 & & Zygomycota \\
\hline 31 & \multirow{9}{*}{ Conventional system } & Filamentous fungi \\
\hline 32 & & Filamentous fungi \\
\hline 33 & & Cladosporium sp. \\
\hline 34 & & Yeast \\
\hline 35 & & Zygomycota \\
\hline 36 & & A. flavus \\
\hline 37 & & Filamentous fungi \\
\hline 38 & & Aspergillus sp. \\
\hline 39 & & Curvularia sp. \\
\hline
\end{tabular}

of S. bicolor in semi-arid of Pernambuco, Brazil, Fusarium and Curvularia were predominant [20].

Fusarium, Cladosporium and Curvularia occurred in leaves of both sorghum genotypes analyzed in the present study, confirming that these genera commonly establish mutualist association with plants, although they are also reported as phytopathogenic [21]. Fusarium for example is commonly found as phytopathogen as well as endophyte, i.e., without causing any apparent damage to the plant, what proves that a microorganism can live only part of its life cycle as an endophyte and develop different types of association, what may lead to the production of different metabolites [22].

Many biotic and abiotic factors influence in endophytic community of the same vegetal species, such as geographical location, climate, agricultural practices, plant tissue and microbial soil composition, thus EF occupy millions of unique ecological niches in many environments $[23,24]$. These factors play an important role in determining the structure and composition in the communities present in the endosphere [25]. Different methods of study, such as culture-independent methods, also influence in the endophytic community. Thus, each research may show a core group of species consistently isolated from any given host as well as long lists of incidental species, including new taxa [26].

Characteristics of plant host are also important features that influence endophytic community 
composition. S. bicolor (L.) Moench is a well-known crop and its rusticity, high biomass production and great tolerance to water deficit are often mentioned [27]. By the other hand, research about how sorghum genotype influences in its endophytic community composition are scarce. Studies in this area have shown that monoculture, cultivation techniques and plant genotype change bacterial and fungal diversity in soil [28-31]. Microbial community in soil may reflect in endophytic fungal composition, but more detail work is necessary to correlate plant genotype and cultivation systems with endophytic fungal communities of sorghum.

Qualimax genotype is a hybrid obtained by the crossing of saccharine and dry stems varieties and when compared to others sorghum genotypes it is considered superior due to its high adaptability to regions of harsh climate [27]. The results stand out Aspergillus spp. as a predominant endophyte of Qualimax. Aspergillus is a ubiquitous genus that produces asexual spores named conidia and its members possess the ability to grow under a wide range of temperature, $\mathrm{pH}$, osmotic pressure, carbon source and oxygen concentration, and can establish different symbiotic relationships, such as parasitism, saprophytism and mutualism [32]. As a versatile and well-adapted fungus, it is possible that Aspergillus is overlapping other fungal genera more sensitive to biotic variations such as the characteristics of the Qualimax genotype.

Semi-arid region of Brazilian Northeast characterized by high temperatures, with an annual average of $25^{\circ} \mathrm{C}$, and a low annual average rainfall of approximately $450 \mathrm{~mm}$ [33]. EF that habit tissues of plants in semi-arid regions are well adapted to such conditions, making then an important source for agricultural appliance aimed to increase crop production under saline and drought stresses, for example [34].

Despite the recognized importance of EF for crops such as sorghum, researches focus mostly on diversity and biotechnological application of endophytic bacteria [35]; what emphasizes the lack of studies about EF, and even more in semi-arid region. Additionally, when the objective of the research is the plant microbiota, it is important not to exclude any group of microorganism, but consider the interactions between bacteria and fungi endophytes [36, 37].

\subsection{Antibacterial Activity}

\subsubsection{Screening and Agar Plug Assay}

Among the $25 \mathrm{EF}$ tested, 23 showed antimicrobial activity against at least one of the bacteria, Gram-positive or Gram-negative (Table 4). Four fungal isolates A. niger (19), A. niger (58), Zygomycota (51) and A. flavus (06) did not show any antimicrobial activity.

The inhibition zones varied from $6.3 \mathrm{~mm}$ up to 29.3 $\mathrm{mm}$ of diameter. Fusarium sp. (16) showed the best result against $B$. subtillis with an inhibition zone of $29.3 \mathrm{~mm}$, as well as Penicillium sp. (61) against $S$. aureus, followed by Aspergillus sp. (38) with an inhibition zone of $28.3 \mathrm{~mm}$ against $B$. subtillis and $25.3 \mathrm{~mm}$ against $S$. aureus (Table 4).

It was also observed that Syncephalastrum sp. (50), Fusarium sp. (42), Aspergillus sp. (59), A. niger (07) and Penicillium sp. (46) inhibited the growth of all bacteria, thus representing a wide spectrum of action.

EF inhabit the interior of plant tissues; this constant interaction, associated with abiotic factors, generates the production of metabolites as response [38]. These metabolites may have biotechnological applications, as they are biologically active, including enzymes [39], amino acids, vitamins, antibiotics, pigments [40, 41], antitumor agents [42], plant growth factors [43], anthelmintics and antifungals [44]. The results of the present research show that EF from S. bicolor produce antibacterial compounds.

According to Schulz and Boyle [45], most species of Acremonium, Alternaria, Cladosporium, Fusarium, Phoma, Pleospora and Phomopsis are considered a rich source of compounds of biotechnological 
Table 4 Inhibitions zones of EF against bacteria.

\begin{tabular}{|c|c|c|c|c|}
\hline \multirow{2}{*}{$\mathrm{EF}\left(\mathrm{n}^{0}\right)$} & \multicolumn{4}{|c|}{ Inhibition zones - Ø mm } \\
\hline & E. coli & K. pneumonie & S. aureus & B. subtilis \\
\hline A. flavus (02) & 10.3 & - & 23.6 & - \\
\hline A. flavus (36) & 19.3 & 20.6 & 20.6 & - \\
\hline A. flavus (06) & - & - & - & - \\
\hline A. niger (53) & 18.3 & 20.3 & 21.3 & - \\
\hline A. niger (19) & - & - & - & - \\
\hline A. niger (56) & 19.0 & 17.0 & 17.3 & - \\
\hline A. niger (58) & - & - & - & - \\
\hline A. niger (08) & 16.6 & 21.0 & - & - \\
\hline A. niger (04) & 13.0 & 12.3 & - & - \\
\hline A. niger (01) & 16.0 & 14.3 & - & - \\
\hline A. niger (07) & 19.7 & 19.3 & 19.7 & 21.3 \\
\hline Aspergillus sp. (59) & 19.0 & 19.7 & 19.7 & 21.3 \\
\hline Aspergillus sp. (38) & - & 21.6 & 25.6 & 28.3 \\
\hline Curvularia sp. (03) & 6.3 & 6.7 & 15.0 & - \\
\hline Fusarium sp. (42) & 14.0 & 13.3 & 15.7 & 16.7 \\
\hline Fusarium sp. (05) & 11.7 & 8.3 & 12.5 & - \\
\hline Fusarium sp. (16) & - & 18.6 & 23.6 & 29.3 \\
\hline Penicillium sp. (46) & 14.3 & 13.3 & 15.7 & 16.7 \\
\hline Penicillium sp. (61) & - & 14.0 & 29.3 & 25.0 \\
\hline Syncephalastrum sp. (50) & 11.3 & 9.3 & 11.2 & 16.0 \\
\hline Zygomycota (52) & 13.0 & 3.0 & - & - \\
\hline Zygomycota (51) & - & - & - & - \\
\hline Filamentous fungi (48) & 11.7 & 9.3 & 22.3 & - \\
\hline Filamentous fungi (18) & 18.3 & 18.3 & - & - \\
\hline Filamentous fungi (37) & 18.3 & 12.3 & 23.6 & - \\
\hline
\end{tabular}

- : no inhibition.

interest because of their production of new metabolites. The current study presented that Aspergillus sp. showed antibacterial activity against $S$. aureus, B. subtilis, E. coli and K. pneumoniae. The genus Aspergillus is also notable for producing a wide variety of both primary and secondary metabolites, including amino acids, vitamins, pigments and antibiotics [46].

The endophyte Fusarium sp. (42) was also isolated in the present study and inhibited the growth of all test bacteria, and Fusarium sp. (16) which also inhibited all bacteria, but not $E$. coli. In a similar study, isolates of the medicinal plant Aquilaria sinensis were tested and found that species of the genus Fusarium inhibited the growth of B. subtilis, S. aureus and $E$. coli [47].
The variety of secondary metabolites produced by a single endophyte has not been estimated yet [48]. Some studies report that certain EF produce compounds equally present in their hosts, for example some enzymes (cellulase and lignase) produced by Xylaria sp. and growth factors such as gibberellin produced by Fusarium; and also antitumor substances such as taxol in Taxomyces andreanae, among others. This fact suggests a transposition of genes between plants and fungi into a real in vivo genetic engineering $[49,50]$.

\subsubsection{Fermentation and Disk Diffusion Assay}

Aiming to optimize the production of metabolites, four isolates were cultured in liquid medium and the crude extracts at different times were analyzed. Syncephalastrum sp. (50), A. niger (56), A. niger (07) 

and Crop Systems and Evaluation of Antimicrobial Activity

and Aspergillus sp. (59) were selected since they had higher inhibition zones as well as a wide spectrum in the agar plug assay.

Aspergillus sp. (59) showed inhibition zone of 25.7 $\mathrm{mm}$ against $E$. coli and $23.3 \mathrm{~mm}$ against $S$. aureus, both at $120 \mathrm{~h}$, followed by Syncephalastrum sp. (50) with a $26.7 \mathrm{~mm}$ mean inhibition zone at $96 \mathrm{~h}$ against $S$. aureus and $23.3 \mathrm{~mm}$ against B. subtillis (Table 5). A. niger (56) had the lowest inhibition with a halo of 5.7 $\mathrm{mm}$ against $K$. pneumoniea at $72 \mathrm{~h}$, and reached only $9 \mathrm{~mm}$ at $120 \mathrm{~h}$. In general, it was observed that there was an increase even if discrete in the production of the antimicrobial compound in liquid medium along cultivation time (Table 5).

Microorganisms control the biosynthesis of metabolites using regulatory mechanisms to avoid overproduction. In some cases, the regulatory mechanisms process low levels that are undesirable for biotechnological application, then the optimization of physical and/or chemical factors can increase the output of the bioactive compounds [51]. In order to proceed with bioprospecting, it is necessary to verify if the microorganism still produces the bioactive compound in liquid culture medium, since it is under this condition that experiments are conducted in industrial scales. Large-scale production brings benefits such as higher production of microbial biomass and consequently greater production of the compound of interest [52].

In this work, culturing time was the optimization factor evaluated, i.e., the crude extracts of fungi that showed the best results in agar plug assay were evaluated after 72, 96 and $120 \mathrm{~h}$ of culture in liquid medium. The best results were showed by Aspergillus sp. (59) and A. niger (56) that after $120 \mathrm{~h}$ of culture showed inhibition zones of $23.3 \mathrm{~mm}$ and $25.3 \mathrm{~mm}$ against $S$. aureus, respectively, and $25.7 \mathrm{~mm}$ and 26.3 mm against $E$. coli, respectively. A similar research developed by Siqueira et al. (2011) [26] found that between $72 \mathrm{~h}$ and $96 \mathrm{~h}, \mathrm{pH} \mathrm{5-7}$ and malt extract culture medium were the best culture conditions for the production of the bioactive compounds. Among 16 EF submitted to the fermentation test, 10 exhibited antimicrobial activity. From these, 90\% showed activity against $S$. aureus, $30 \%$ against $B$. subtilis and $10 \%$ against $K$. pneumoniae, with inhibition halos varying from $13 \mathrm{~mm}$ to $25 \mathrm{~mm}$.

Merlin et al. (2013) [53] conducted a research that aimed the optimization of culture conditions and the results showed that $9 \mathrm{~d}$ of incubation was the ideal time for the production of antibacterial metabolites, at the 10th day the production was slightly lower. The

Table 5 The antimicrobial activity of the fermentation liquid.

\begin{tabular}{llllll}
\hline & \multicolumn{5}{c}{ EF } \\
\cline { 2 - 6 } & Time (h) & 59 & 56 & 50 & 07 \\
\cline { 2 - 6 } S. aureus & 72 & 21.3 & 23.3 & 24.0 & 18.7 \\
& 96 & 19.3 & 20.7 & 26.7 & 20.0 \\
\hline \multirow{3}{*}{ E. coli } & 120 & 23.3 & 25.3 & 26.7 & 20.0 \\
& 72 & 25.0 & 24.7 & 9.7 & 11.0 \\
& 96 & 24.7 & 24.0 & 12.3 & 11.7 \\
B. subtilis & 120 & 25.7 & 26.3 & 12.3 & 18.7 \\
& 72 & 17.0 & 8.3 & 23.3 & 18.7 \\
\hline \multirow{3}{*}{ K. pneumonie } & 96 & 16.0 & 9.3 & 25.0 & 18.7 \\
& 120 & 18.7 & 12.7 & 25.0 & 10.3 \\
\hline A. & 72 & 21.0 & 5.7 & 12.0 & 10.7 \\
\hline
\end{tabular}

A. niger (56); A. niger (07); Aspergillus sp. (59); Syncephalastrum sp. (50). 

and Crop Systems and Evaluation of Antimicrobial Activity

production of antibacterial compounds follows the kinetics of fungal growth, so the highest production of a secondary metabolite often occurs during the sporulation stage of the microorganism [54]. Oliveira et al. (2011) [55] used fungal extracts obtained directly from the fermented culture medium kept under agitation for $9 \mathrm{~d}$ and there was a greater number of susceptible bacteria with mean inhibition zones ranging from $6.0 \mathrm{~mm}$ to $12.5 \mathrm{~mm}$ in diameter against Salmonella enterica and S. aureus. As well as, a study developed by Wenzel et al. (2013) [56] in which the extracts obtained from the fermented medium presented antimicrobial activity against $E$. coli and $S$. enterica.

In the present study, all fungi tested in liquid medium maintained their ability to produce the antibacterial compound under this condition. In general, it was observed that inhibition zones increased when the culture time was longer. Although this result is expected once inasmuch as longer cultivation time the greater the fungal biomass, studies indicate that a substantial reduction in the production of these molecules in axenic culture is common. In other words, no more interaction with the host or with other organisms may imply that there is no need to produce the compound anymore [57]. Thus, the results obtained in this work show a good potential of these fungi to be used in future experiments on a larger scale.

\section{Conclusions}

Several studies have revealed the positive effect of EF to its hosts, including higher resistance to abiotic and biotic stresses. Although their importance and their application in agriculture and biotechnology are recognized, there are few studies about EF from sorghum in Brazilian semi-arid region. In the present work, Aspergillus spp. composed the major fraction of EF, mainly from Qualimax genotype. This result indicates that characteristics of the plant may induce a selection of better-adapted fungi, which may interfere other fungal species and diminish the diversity of the endophytic community.

\section{References}

[1] Gomes, S. O., Pitombeira, J. B., Neiva, J. N., and Cândido, M. J. D. 2006. "Agronomic Behavior and Chemical-Bromatological Composition of Forage Sorghum Cultivars in the State of Ceará." Rev. Cienc. Agron. 37: 221-7. (in Portuguese)

[2] Arnold, A. E., Maynard, Z., Gilbert, G. S., Coley, P. D., and Kursar, T. A. 2000. "Are Tropical Endophytes Fungi Hyperdiverse?" Rev. Ecology Letters. 3: 267-74.

[3] Strobel, G., and Daisy, B. 2003. "Bioprospecting for Microbial Endophytes and Their Natural Products." Microbiology and Molecular Biology Review 67: 491-502.

[4] Tan, R. X., and Zou, W. X. 2001. "Endophytes: A Rich Source of Functional Metabolites." Nat. Prod. Rep. 18: 448-59.

[5] Pocasangre, L., Sikora, R. A., Vilich, V., and Schuster, R. P. 2000. "Survey of Banana Endophytic Fungi from Central America and Screening for Biological Control of the Burrowing Nematode (Radopholus similis)." Acta. Horticulturae 53: 283-90.

[6] Araújo, W. L., Maccheroni, J. W., Aguilar-Vildoso, C. I., Barroso, P. A. V., Saridakis, H. O., and Azevedo, J. L. 2001. "Variability and Interactions between Endophytic Bacteria and Fungi Isolated from Leaf Tissues of Citrus Rootstocks." Can J. Microbiol 47: 229-36.

[7] Luz, J. S., Silva, R. L. O., Silveira, E. B., and Cavalcante, U. M. T. 2006. "Enzymatic Activity of Endophytic Fungi and Effect on Growth Promotion of Yellow Passion Fruit Seedlings." Revista Caatinga 19 (2): 128-34. (in Portuguese)

[8] Zida, E. P., Thio, I. G., Néya, B. J., O'Hanlon, K., Deleuran, L. C., Wulff, E. G., Lund, O. S., Shetty, P. H., and Boelt, B. 2014. "Fungal Endophytes of Sorghum in Burkina Faso: Occurrence and Distribution." African Journal of Microbiology Research 8 (46): 3782-93.

[9] Araújo, W. L., Lima, S. O. A., Azevedo, J. L., Macron, J. L., Sobral, J. K., and Lavaca, P. T. 2002. "Manual: Isolation of Endophytic Microorganisms." CALQ, Piracicaba. (in Portuguese)

[10] Carroll, G. C., and Carroll, F. E. 1978. "Studies on the Incidence of Coniferous Needle Endophytes in the Pacific Northwest." Can. J. Bot. 56: 3034-43.

[11] Booth, C. 1971. The Genus Fusarium. Commonwealth Mycological Institute, Kew, Surrey, England.

[12] Ellis, M. B. 1971. Dematiaceous Hyphomycetes. Commowealth Mycological Institute, Kew, England, 608. 

and Crop Systems and Evaluation of Antimicrobial Activity

[13] Ellis, M. B. 1976. More Dematiaceous Hyphomycetes. Commowealth Mycological Institute, Kew, England, 507.

[14] Barnett, H. L., and Hunter, B. B. 1987. Illustrated Genera of Imperfect Fungi. 4th edition. The American Phytopathological Society, St. Paul, Minessota, USA.

[15] Hanlin, R. T. 2000. Illustrated Genera of Ascomycetes. Volume II. The American Phytopathological Society, Minessota, USA.

[16] Ichikawa, T., Ishikura, T., and Ozaki, A. 1971. "Improvement of Kasugamycin-Producing Strain by the Agar Piece Method and the Prototroph Method." Folia. Microbiol.16: 218.

[17] Bauer, A. M., Kirby, W. M. M., Sherris, J. C., and Turck, M. 1996. "Antibiotic Susceptibility Testing by a Standardized Single Disk Method." Am. J. Clin. Pathol. 43: 493-6.

[18] Vandenkoornhuyse, P., Quaiser, A., Duhamel, M., and Dufresne, A. 2015. "The Iimportance of the Microbiome of the Plant Holobiont." New Phytol. 206: 1196-206.

[19] Schlaeppi, K., and Bulgarelli, D. 2015. "The Plant Microbiome at Work." Current Review 28 (3): 212-7.

[20] Silva, R. M. F., Silva, M. I. S., Oliveira, R. J. V., Calvacanti, M. A. Q., Tabosa, J. N., and Bezerra, J. L. 2015. "Preliminary Studies of Endophytic Fungi on Roots of Sorghum bicolor L. Moench, Collected in Goiana/PE." In Annals of the XXXV Brazilian Congress of Soil Sciences, ISBN 978-85-86504-14-3 Natal, RN, Brasil. (in Portuguese)

[21] Marin-Felix, Y., Groenewa, J. Z., Cai, L., Chen, Q., Marincowitz, S., Barnes, I., Bensch, K., Braun, U., Camporesi, E., Damm, U., de Beer, Z. W., Dissanayake, A., Edwards, J., Giraldo, A., Hernández-Restrep, M., Hyde, K. D., Jayawardena, R. S., Lombard, L., Luangsa-ard, J., McTaggart, A. R., Rossman, A. Y., Sandoval-Denis, M., Shen, M., Shivas, R. G., Tan, Y. P., van der Linde, E. J., Wingfield, M. J., Wood, A. R., Zhang, J. Q., Zhang, Y., and Crous, P. W. 2017. "Genera of Phytopathogenic Fungi: GOPHY 1.” Stud. Mycol. 86 (March): 99-216. doi: 10.1016/j.simyco.2017.04.002.

[22] Bernardi-Wenzel, J. 2012. "Isolation and Antagonistic Activity of Soybean Endophytic Fungi (Glycine max (L.) Merrill)." SaBios-Journal of Health and Biology 7 (3): 1.

[23] Bandara, W. M. M. S., Seneviratne, G., and Kulasooriya, S. A. 2006. "Interactions among Endophytic Bacteria and Fungi: Effects and Potentials.” J. Biosci. 31 (5): 645-50.

[24] Stone, J. K., Polishook, J. D., and White-Júnior, J. F. 2004. "Endophytic Fungus." In Biodiversity of Fungi; Inventory and Monitoring Methods, Mueller, J. M., Bills, G. F., and Foster, M. S. (eds), San Diego: Elsevier Academic Press, 241-70.

[25] Seghers, D., Wittebolle, L., Top, E. M., Verstraete, W., and Siciliano, S. D. 2004. "Impact of Agricultural
Practices on the Zea mays L. Endophytic Community." Applied and Environmental Microbiology 70 (3): 1475-82.

[26] Siqueira, V. M., Conti, R., Araújo, J. M. E., and Souza-Motta, C. M. 2011. "Endophytic Fungi from the Medicinal Plant Lippia sidoides Cham. and Their Antimicrobial Activity." Symbiosis 53: 89-95.

[27] Costa, R. F., Pires, D. A. A., Moura, M. M. A., Sales, E. C. J., Rodrigues, J. A. S., and Rigueira, J. P. S. 2016. "Agronomic Characteristics of Sorghum Genotypes and Nutritional Values of Silage." Animal Sciences 38 (2): 127-33.

[28] Liang, M. Q., Zhang, C. H. F., Peng, C. H. L., Lai, Z. L., Chen, D. F., and Chen, Z. H. 2010. "Plant Growth Community Structure and Nutrient Removal in Monoculture and Mixed Constructed Wetlands." Rev. Ecol. Eng. 37: 309-16.

[29] Schlemper, T. R., Leite, M. F. A., Lucheta, A. R., Shimels, M., Bouwmeester, H. J., van Veen, J. A., and Kuramae, E. E. 2017. "Rhizobacterial Community Structure Differences among Sorghum Cultivars in Different Growth Stages and Soils." FEMS Microbiology Ecology 93 (8): 1-11.

[30] Schlemper, T. R., van Veen, J. A., and Kuramae, E. E. 2017. "Co-variation of Bacterial and Fungal Communities in Different Sorghum Cultivars and Growth Stages Is Soil Dependent.” Microb. Ecol. 76 (1): 205-14. https://doi.org/10.1007/s00248-017-1108-6.

[31] Gałązka, A., and Grządziel, J. 2018. "Fungal Genetics and Functional Diversity of Microbial Communities in the Soil under Long-Term Monoculture of Maize Using Different Cultivation Techniques." Front. Microbiol. 9: 76. doi: 10.3389/fmicb.2018.00076.

[32] Bennett, J. W. 2010. "An Overview of the Genus Aspergillus." In Aspergillus: Molecular Biology and Genomics, Caister Academic Press.

[33] Moura, M. S. B., Galvincio, J. D., Brito, L. T. L., Souza, L. S. B., Sá, I. I. S., and Silva, T. G. F. 2007. "Climate and Rainwater in the Semi-arid." In Potentialities of Rainwater in the Brazilian Semi-arid, Brito, L. T. L., Moura, M. S. B., and Gama, G. F. B. (eds), Petrolina, Embrapa Semi-Árido, 37-59. (in Portuguese)

[34] Singh, L. P., Gill, S. S., and Tuteja, N. 2011. "Unraveling the Role of Fungal Symbionts in Plant Abiotic Stress Tolerance.” Plant Signal. Behav. 6 (2): 175-91.

[35] Maropola, M. K. A., and Ramond, J. B. 2015. "Impact of Metagenomic DNA Extraction Procedures on the Identifiable Endophytic Bacterial Diversity in Sorghum bicolor (L.) Moench." Journal of Microbiological Methods $112 \quad$ (2015): 104-17. doi: 10.1016/j.mimet.2015.03.012.

[36] Lackner, G., Moebius, N., and Hertweck, C. 2011. 

and Crop Systems and Evaluation of Antimicrobial Activity

"Endofungal Bacterium Controls Its Host by and Hrp Type III Secretion System." The ISME Journal 5 (2): 252-61.

[37] Hoffman, M. T., Gunatilaka, M. K., Wijeratne, K., Gunatilaka, L., and Arnold, A. E. 2013. "Endohyphal Bacterium Enhances Production of Indole-3-Acetic Acid by a Foliar Fungal Endophyte." PLOS ONE 8 (9): e731-32.

[38] Pusztahelyi, T., Holb, I. J., and Pócsi, I. 2015. "Secondary Metabolites in Fungus-Plant Interactions." Front Plant Sci. 6: 573. doi: 10.3389/fpls.2015.00573.

[39] Santos, T. T., and Varavallo, M. A. 2011. "Application of Endophytic Microorganisms in Agriculture and in the Production of Substances of Economic Interest." Semina: Biological and Health Sciences 32 (2): 199-212. (in Portuguese)

[40] Demain, A. L. 1992. "Microbial Secondary Metabolism: A New Opportunity for Industry." Ciba Foundation Symposium 3-23.

[41] Pimentel, M. R., Molina, G., Dionísio, A. P., Maróstica-Jr, M. R., and Pastore, G. M. 2011. "The Use of Endophytes to Obtain Bioactive Compounds and Their Application in Biotransformation Process." Biotechnology Research International, Article ID 576286. doi: $10.4061 / 2011 / 576286$.

[42] Wang, J., Li, G., Lu, H., Zheng, Z., Huang, Y., and Su, W. 2000. "Taxol from Tubercularia sp. Strain TF5, an Endophytic Fungus of Taxus mairei." FEMS-Microbiology Letters 193: 249-53.

[43] Alexopoulos, C. J., and Mims, C. W. 1996. Introductory Mycology. 4th edition. John Wiley \& Sons INC, USA, 869.

[44] Cragg, M. G., and Newman, D. J. 2005. "Biodiversity: A Continuing Source of Novel Drug Leads." Pure and Applied Chemistry 77: 7-24.

[45] Schulz, B., and Boyle, C. 2005. "The Endophytic Continuum.” Mycological Research 109: 661-86.

[46] Houbraken, J., Vries, R. P. E., and Samson, R. A. 2014. "Modern Taxonomy of Biotechnologically Important Aspergillus and Penicillium Species." Adv. Appl. Microbiol 86: 199-249.

[47] Cui, J. L., Guo, S. X., and Xiao, P. G. 2011. "Antitumor and Antimicrobial Activities of Endophytic Fungi from Medicinal Parts of Aquilaria sinensis." Journal of
Zhejiang University (Biomedicine \& Biotechnology) 12 (5): 385-92.

[48] Azevedo, J. L., Maccheori, W. J., Araújo, W. L., and Pereira, J. O. 2002. "Endophytic Microorganisms and Their Role in Tropical Plants." In Biotechnology: Advances in Agriculture and Agroindustry, Serafini, L. A., Barros, N. M., and Azevedo, J. L. (eds), Caxias do Sul: EDUCS.

[49] Azevedo, J. L. 1998. "Endophytic Microorganisms." In Microbial Ecology, Melo, I. S., and Azevedo, J. L. (eds), Jaguariúna: EMBRAPA, 117-37.

[50] Pamphile, J. A., and Azevedo, J. L. 2002. "Molecular Characterization of Endophytic Strains of Fusarium verticillioides (Fusarium moniliforme) from Maize (Zea mays L.)." World Journal of Microbiology \& Biotechnology 18 (5): 391-6.

[51] Mathan, S., Subramanian, V., and Nagamony, S. 2013. "Optimization and Antimicrobial Metabolite Production from Endophytic Fungi Aspergillus terreus KC 582297.” Eur. J. Exp. Biol 3: 138-44.

[52] Kusari, S. M. 2011. "Are We Ready for Industrial Production of Bioactive Plant Secondary Metabolites Utilizing Endophytes?" Natural Product Reports 28: 1203-7.

[53] Merlin, J. N., Christhudas, I. V. S., Kumar, P. P., and Agastian, P. 2013. "Optimization of Growth and Bioactive Metabolite Production: Fusarium solani." Asian J. Pharm. Clin. Res. 6 (3): 98-103.

[54] Takahashi, J. A., and Lucas, E. M. F. 2008. "Occurrence and Structural Diversity of Fungal Metabolites with Antibiotic Activity." New Chemistry 31 (7): 1807-13.

[55] Oliveira, F. B. M., Lima, L. M., Moura, M. E. B., Nunes, B. M. V. T., and Oliveira, B. M. 2011. "Indiscriminate Use of Antibiotics and Microbial Resistance: A Reflection on the Treatment of Hospital Infections." Revista Interdisciplinar NOVAFAPI 4 (4): 72-7. (in Portuguese)

[56] Wenzel, J. B., Almeida-Moresco, A. A., Boas, E. V., Burin, F. A. G., and Souza, R. O. 2013. "Enzymatic and Antimicrobial Activity of Endophytic Fungi Isolated from Soybean.” Biológicas \& Saúde3 (9): 1-15.

[57] Scherlach, K., and Hertweck, C. 2009. "Triggering Cryptic Natural Product Biosynthesis in Microorganisms." Organic \& Biomolecular Chemistry 7: 1753-60. 